\title{
The Influence of Traditional Views, Ethics and Religions on the Development of Modern Medical Technology
}

\author{
Na Wang \\ Department of Anesthesiology \\ The First Hospital of Jilin University \\ Changchun, China \\ wangna080613@163.com
}

\author{
Corresponding author: Jinguo Wang* \\ Department of Urology \\ The First Hospital of Jilin University \\ Changchun, China \\ wangjinguo@163.com
}

\begin{abstract}
The effects of traditional views, ethics and religions on the modern medical technology were analyzed in this paper. Conflicts result from the relative stability of social ethics and the rapid development of science and technology. By analyses of the traditional culture influence on modern people's psychology, we analyze these traditional ideas impact on modern medical technology development, such as the application of organ transplanting, euthanasia and clone technology. We conclude that the affection is mutual.
\end{abstract}

Keywords-traditional views; ethics; organ transplantation; euthanasia; clone technology; religion

\section{INTRODUCTION}

The international human genome organization, scientific and cultural organization, world health organization, etc., have on the human genome research, cloning and other ethical issues published documents. The United Nations has set up a special committee on human cloning legislation problems and proposed legislation to ban reproductive cloning in the name of the United Nations. The research of medical science ethics originated in the west, though less in foreign related monographs, but more journal articles. Abroad for medical technology ethical questions research focuses on the analysis of specific ethical problems caused by modern medical technology, for the cause analysis of the causes of ethical questions. Medical ethics, the researchers had no further analysis to treat the patient's cultural background such reasons. In fact, the western individualism, pay attention to the cultural background of individual rights make this kind of seeking truth from facts to tell patients condition for doctors and patients. In the west by the patients themselves completely decide whether to accept treatment, and what kind of treatment.

\section{PREVIOUS STUdIES}

Many articles on some journals on the ethical problems caused by modern medical technology have become the research important place of medical ethics. Modern medical technology in China are the trigger monograph also many ethical problems, the study by the domestic large ethical dispute caused by modern medical technology are discussed in this paper, analysis, points out the main ethical questions they raise, discussed the modern medical technology should follow the principle of medical ethics, but less analysis of the medical technology causing the deep reasons of the ethical controversy [1].

Since entering the $21 \mathrm{st}$ century, with the rapid development of high and new science and technology, some contradictions and problems also become more prominent, people gradually realize the importance of science and technology development of humanistic care. Some scholars of the humanistic factors affecting the development of high-tech are discussed, and some scholars to reduce the negative effect of science and technology development is also put forward its own proposals. This treatise also gives the author write the ethical thinking of the modern medical technology "a lot of inspiration.

\section{A. Foreign research}

It can be seen from the analysis of the present status of research on this problem, the domestic and foreign research focused on the analysis of the specific ethical problems caused by medical technology, for the cause of the problem and countermeasure research is few, the status and the rapid development of modern medical technology and the significant influence to the social ethics can't adapt to the reality. But previous studies are also for this thesis about "the ethical thought of modern medical technology" writing provides a number of theoretical support and reference.

Economy is a modern medical technology is an important cause of ethical questions. Social being determines social consciousness, the emergence and development of ethics is fundamentally determined by the social existence. The world into a period of relative peace, get faster economic development, provides a basis for the social progress of other. In the $1960 \mathrm{~s}$, medical science has achieved the unprecedented achievement, life support the development of the technology, organ transplant technology, make people begin to question the traditional cardiopulmonary death standard. Harvard standard "in 1968, Harvard Medical School puts forward" the brain death standard, caused the widespread discussion, people began to re-examine the traditional idea and basic moral 
assumptions, such as: rethinking the purpose of the medical standard, the value of life and death, etc.

The Netherlands is the first country legalizing euthanasia is closely related to its economic development. Such as the Netherlands on the health care system is different with other countries, in the world, the Dutch medical services can be said to be one of the highest level. Have private health insurance accounted for more than $95 \%$ in the number of citizens. Dutch palliative care very progress, many hospitals have pain control and palliative care center, it is can't compare with other countries. And the Dutch family doctor system is the country's most of the patients and physicians have long-term cooperative relations, which is less in other countries. Because they have such perfect medical security system, can perform for euthanasia legislation on economic security. If poor countries, most of the elderly pension is not by society but by children, perhaps euthanasia for those who are not willing to provide for the old man provides an excuse. And for some no one support of the old man, after sick they may put euthanasia as a way of suicide.

\section{B. Economic influence}

Economic ethical questions of modern medical technology to produce the final decision effect, only the economic development, people's living standard and life quality can be further improved, in this premise, possible only because euthanasia talent "near-death, painful", but will not appear due to cannot afford the high medical costs and support the practice of euthanasia [2].

\section{The INFLUENCE OF TRADitional CUlture}

The influence of traditional culture and modern medical technology ethics problem is one of the important reasons. Ethics is belong to the category of ideology, and is based on certain cultural background, is a part of social culture. Medicine is all mankind to share the achievements of science and technology, the promotion and use of it can bring benefits to people all over the world, but the ethics of medical technology is closely connected with national cultural inheritance and specific national conditions. As medical historian said, make the canvas with general culture, draw on medical panoramic view. The value judgment of modern medical technology, different culture, different ideology and different religion will inevitably produce different ethical and moral concept. Abortion is ethical, for example, people of different cultural traditions will make a different answer. The culture of each country all has a obvious impact on the country's medical ethics. The formation and development of modern medical ethics in our country are mainly in ancient significantly influence of religious and cultural thoughts. Western medical ethics system is influenced by western ideology and culture and it also absorbed various religious and ethical philosophy and secular morality.

People's opinions about application and development of modern medical technology are inevitably influenced by Confucian traditional culture concept. For example, our country is under the influence of the Confucian concept of "filial piety", people always hope their elders "happiness as immense as the Eastern Sea, live as long as the southern mountain", even if parents elders with fatal diseases, also always try our best to heal, for its one thousand ways to prolong their lives.

Euthanasia is actually a kind of advocate the premature death of foreign culture, and the traditional Chinese concept of "filial piety" is inconsistent. The traditional concept of autopsy unfilial has seriously hindered the development of TCM anatomy, but also led to the modern one of the cause of the serious lack of donor organ transplantation technology.

On the value of life Confucian, Taoist more than they save lives as the first, and established the theory and method of preserve one's health. On the relationship between life and death, the Taoist view is unique, put forward the idea of a body, the good life good death, life and death view death as the arrangement of the heaven and earth natural, think people as long as can comply with the nature, the most important thing is to keep the existence of life and the pursuit of high quality of life. Confucianism, Taoism thought deeply influenced the Chinese society [3].

Although euthanasia can relieve dying patients of pain and reduce patient family burden, to save health resources, but now euthanasia in our country is not easy. Because of the list in terms of ethics, we always have the idea of rebirth evil dead, aged respected, his father's virtue, if let children have not stopped breathing parents decide to euthanasia, for not stop breathing wife or husband decided to euthanasia, it is hard to do right now.

\section{The Current Status In ChinA}

In China, a lot of people affected by traditional culture concept, if a patient is euthanasia, the doctor and the patient's family will be condemned by public opinion. Euthanasia will encounter the obstacles of traditional culture, as a result, the lack of legalizing the ideological basis.

Our country has more than two thousand years of feudal society background, influenced by Confucian ethics thought for a long time, for a Chinese family is of great significance. The family is the basic unit of society, is the most basic and most core unit. Therefore, personal interests and rights have been placed under family. In medical treatment, the family will play a decisive role for the individual to make decisions, such as scholars mention "patients are often used to put should belong to the medical decisions in the hands of his own family, it has become common, nature rather than against."

Freedom and respect for the individual, advocating personality is western ethics from the ancient Greek and humanistic tradition since the Renaissance [4]. Thai Buddhist ethicists Ratanakul once said: "north American bioethics onesided focus on the rights of the individual and individual, and personal and social requirements to others; it seldom focus on individual and social responsibility to others, this is the symbol of American culture. But in Asian culture, these are the values that are unacceptable. The fundamental characteristics of the medical ethics research are individualistic values. Americans believe dignity and sanctity of the individual. Any intervention in personal way he thinks 
is right thinking, judgment, decision making and the behavior of life is not only immoral, and is a profanation. Can say, the United States is the highest ideal of individualism, the most noble social ideal and world view and individualism. For Americans, abandon individualism, is to give up his most. The identity of one of the most vital Puritanism has profound influence to American culture, to say the Puritanism is the root of American culture. American individualism derived from the reasonable principle of Puritanism, derived from Puritanism in the pursuit of individual autonomy.

Generate operating concept art to life. It is in the Taoist philosophy of life, under the influence of door, good living, because of your birth and, in turn pays attention to preserve one's health [5]. Taoism is by far the most emphasis on your life Chinese traditional religion, all the activities of it is the continuation of the existence of human life and survival time for the purpose.

Taoism is not only recognized the Confucian "body hair skin, by the parents, afraid to damage, the beginning of the filial piety" concept, and to strengthen, become the basic starting point of life ethics. In the door, maintain its own complete and healthy, this is not only the basic requirement of filial to parents, but also is the human must reflect heaven. Taoist concept of rebirth evil death is similar to the Confucian ideas on this, their influence on medical ethics in the front section for instructions, go here. The life philosophy of Taoism and Buddhism world-weariness born evil and Confucian "life and death by life, riches and honor in the day" is in stark contrast, this viewpoint is more beneficial to the development of medicine.

Compared with our country, the deeper influence on the western ideas is religion. In America, for example, the United States has the religious in the developed countries. Contemporary Christian a few basic principles: first, the thought of life from god, anyone can't take control of your own body. Second, life divine principle: life is given by god and is sacrosanct.

Integrity principle: that the existence of the part is for the overall good, and if necessary, you can sacrifice the interests of the part for the overall good, but the only principle of Christianity to achieve the overall interest of the individual, and not sacrifice the individual for the benefit of the whole. Christian don't agree with to the development of the medical human trials, also don't agree to give a human organ transplant to another person. Fourth, sexual and reproductive principle: Christian think man's sexual function and other functions, must be in conformity with the purpose of god, and in accordance with the function of natural purpose is used for reproduction, is to maintain the bond of marriage. Modern artificial reproductive technology, organ transplant technology, euthanasia and cloning are strong opposition from Christian, because they think these technologies, against the will of god, people's implementation of these technologies were playing god.

Entrusted agent is based on the authorization of the agent behavior and enjoys the agency. Patients' informed consent principal-agent is at present our country has not related laws and regulations, is that some scholars based on patients' informed consent in medical areas difficult questions, the idea of "the principle of informed consent is patients" barriers to implement difficult main reason lies in the medical profession: patients lack of medical knowledge, the cognitive understanding of a doctor told medical information ability is limited, it is difficult to effectively achieve the goal of informed consent. Patients will be entrusted to an agent or body for informed consent can solve your knowledge can not correctly understand medical treatment information, thus cannot effectively the plight of informed consent. It appears to be in the maintenance of patients right of informed consent, but is strong will be relying on abundant medical information resources between the basic responsibility of the laps patients push to take off to the society, to the patients with add unnecessary trouble, add unnecessary burden to the society, even to the national finance additional expenditure.

Even if all the above can be ignored, entrusted agency informed consent can really solve the problem of patients' informed consent is difficult? Entrusted agency seems feasible, informed consent in fact, its implementing difficulty is quite large. To practice the principal-agent informed consent must first solve the agency subject qualification and cost problem, the following solutions for four hypothesis try not to its feasibility as a simple argument.

\section{SUMMARY}

Some traditional cultural ideology, religion, and the old ethical code of ethics has hindered the application and development of modern medical technology better, the development of modern medical technology requirements of adjusting and reforming the traditional culture, religion and ethical norms change can't adapt to technology development. Ethics is to meet the needs of the development of medical technology, to control and guide effect.

\section{ACKNOWLEDGMENT}

This research was financially supported by the First Hospital of Jilin University.

\section{REFERENCES}

[1] Canadian Agency for Drugs and Technologies in Health. About CADTH http://www.cadth.ca/en/cadth. 2013

[2] Kim, Chang-Yup. Health technology assessment in South Korea. International Journal of Technology Assessment in Health Care. 2009

[3] Jonsson, Egon. History of health technology assessment in Sweden. International Journal of Technology Assessment in Health Care. 2009

[4] Renaldo N, Brigitte H, Matthew J. Health technology assessment in Canada. International Journal of Technology Assessment in Health Care. 2009

[5] Drummond M, Banta D. Health technology assessment in the United Kingdom. International Journal of Technology Assessment in Health Care. 2009 